OPEN ACCESS

Edited by:

Alejandro Isabel Luna-Maldonado, Universidad Autónoma de Nuevo

León, Mexico

Reviewed by:

Hao Peng,

Washington State University, USA

Chong Zhang,

University of Maryland Baltimore

County, USA

*Correspondence:

YuxinTong

tongyuxin@caas.cn

Specialty section:

This article was submitted to

Crop Science and Horticulture,

a section of the journal

Frontiers in Plant Science

Received: 01 December 2015

Accepted: 21 February 2016

Published: 30 March 2016

Citation:

Wang J, Tong $Y$, Yang $Q$ and Xin $M$ (2016) Performance of Introducing

Outdoor Cold Air for Cooling a Plant

Production System with Artificial Light.

Front. Plant Sci. 7:270

doi: $10.3389 /$ fpls.2016.00270

\section{Performance of Introducing Outdoor Cold Air for Cooling a Plant Production System with Artificial Light}

\author{
Jun Wang ${ }^{1,2}$, Yuxin Tong ${ }^{1,2 *}$, Qichang Yang ${ }^{1,2}$ and Min Xin ${ }^{1,2}$ \\ 1 Institute of Environment and Sustainable Development in Agriculture, Chinese Academy of Agricultural Science, Beijing, \\ China, ${ }^{2}$ Key Laboratory of Energy Conservation and Waste Management of Agricultural Structures, Ministry of Agriculture, \\ Beijing, China
}

The commercial use of a plant production system with artificial light (PPAL) is limited by its high initial construction and operation costs. The electric-energy consumed by heat pumps, applied mainly for cooling, accounts for $15-35 \%$ of the total electric-energy used in a PPAL. To reduce the electric-energy consumption, an air exchanger with low capacity (180 W) was used for cooling by introducing outdoor cold air. In this experiment, the indoor air temperature in two PPALs (floor area: $6.2 \mathrm{~m}^{2}$ each) was maintained at 25 and $20^{\circ} \mathrm{C}$ during photoperiod and dark period, respectively, for lettuce production. A null $\mathrm{CO}_{2}$ balance enrichment method was used in both PPALs. In one PPAL (PPALe), an air exchanger (air flow rate: $250 \mathrm{~m}^{3} \cdot \mathrm{h}^{-1}$ ) was used along with a heat pump (cooling capacity: $3.2 \mathrm{~kW}$ ) to maintain the indoor air temperature at the set-point. The other PPAL (PPAL ${ }_{C}$ ) with only a heat pump (cooling capacity: $3.2 \mathrm{~kW}$ ) was used for reference. Effects of introducing outdoor cold air on energy use efficiency, coefficient of performance (COP), electric-energy consumption for cooling and growth of lettuce were investigated. The results show that: when the air temperature difference between indoor and outdoor ranged from 20.2 to $30.0^{\circ} \mathrm{C}$ : (1) the average energy use efficiency of the air exchanger was 2.8 and 3.4 times greater than the COP of the heat pumps in the PPAL $L_{e}$ and $P P A L_{c}$, respectively; (2) hourly electric-energy consumption for cooling in the PPAL $L_{e}$ reduced by $15.8-73.7 \%$ compared with that in the PPAL ; (3) daily supply of $\mathrm{CO}_{2}$ in the PPALe reduced from 0.15 to $0.04 \mathrm{~kg}$ compared with that in the $P P A L_{c}$ with the outdoor air temperature ranging from -5.6 to $2.7^{\circ} \mathrm{C}$; (4) no significant difference in lettuce growth was observed in both PPALs. The results indicate that using air exchanger to introduce outdoor cold air should be considered as an effective way to reduce electric-energy consumption for cooling with little effects on plant growth in a PPAL.

Keywords: coefficient of performance, energy saving, heat pump, lettuce, plant factory

\section{INTRODUCTION}

Recently, plant production systems with artificial light (PPAL) have been gradually used for plant growth in Asian countries, like China and Japan, due to their incomparable advantages of year round scheduled high-quality plant production, high resources use efficiencies, little environmental pollutions, etc. (Kozai, 2012; Fang, 2013). Unlike a greenhouse, the wall of a PPAL is constructed 
with opaque thermal insulated materials and artificial lighting is the sole light source for plant growth (Kozai et al., 2006; Li et al., 2012). Heat pumps are often used to remove extra heat generated from artificial lighting to maintain an optimum air temperature. Therefore, the operation cost of a PPAL is high and the commercial use of PPAL is limited. The cost of electricenergy consumed by artificial lighting and heat pumps, accounts for more than $30 \%$ of the total operation cost in a PPAL (Fang, 2013). The electric-energy consumed by heat pumps, accounts for $15-35 \%$ of the total electric-energy consumption in a PPAL, is mainly used for cooling (Nishimura et al., 2001; Ohyama et al., 2001). Therefore, reducing the electric-energy consumption of heat pumps would be helpful for reducing the operation cost of a PPAL.

Several methods were investigated to reduce the electricenergy consumed by heat pumps for cooling: (1) employing light devices with low heat generation, such as light emitting diode (e.g., Poulet et al., 2014), for reducing heat load in a PPAL, (2) changing light intensity at different plant growth stages (e.g., Tong and Yang, 2014), (3) employing movable light systems (e.g., Li et al., 2014), and (4) introducing seasonal ice storage system for cooling (Yang et al., 2012), etc. However, few studies have been reported on reducing electric-energy consumption for cooling by improving the coefficient of performance (COP) or shortening the operation time of heat pumps working with low COP. It has been reported that high COP for cooling is usually achieved when cooling load is $60-80 \%$ of the cooling capacity of a heat pump (Tong et al., 2013). Too low/high heat load reduces the COP. Low heat load also causes frequent ON/OFF operation of heat pumps, which reduces the COP. Outdoor air, whenever its temperature is below the air temperature in the PPAL, is a potential cold source for cooling the air temperature in a PPAL. And therefore direct air exchange may be more energy-efficient than using a heat pump. The main drawback of direct air exchange is that $\mathrm{CO}_{2}$ utilization efficiency would decrease when indoor $\mathrm{CO}_{2}$ concentration needs to be kept at high levels (e.g., $1000 \mu \mathrm{mol}$ $\mathrm{mol}^{-1}$ ) because some of the injected $\mathrm{CO}_{2}$ would be lost during the air exchange process (Tingey et al., 2000). Without $\mathrm{CO}_{2}$ enrichment, $\mathrm{CO}_{2}$ depletion $\left(50-200 \mu \mathrm{mol} \mathrm{mol}{ }^{-1}\right)$ could occur during photoperiod, even with natural ventilation (SanchezGuerrero et al., 2005). Under such conditions, $\mathrm{CO}_{2}$ concentration may become a limiting environmental factor for photosynthesis (Thongbai et al., 2010). Therefore, a null $\mathrm{CO}_{2}$ balance enrichment method, where $\mathrm{CO}_{2}$ concentration is maintained at the same as outdoor level, is proposed to keep high utilization efficiency of supplied $\mathrm{CO}_{2}$ when the outdoor cold air is introduced into a PPAL (Kozai, 2009).

In this study, we investigated air exchanging aided by a heat pump as a primary cooling method. The performance of the cooling method was compared with the cooling method that depended solely on a heat pump. To avoid $\mathrm{CO}_{2}$ depletion and keep a high $\mathrm{CO}_{2}$ utilization efficiency, the null $\mathrm{CO}_{2}$ balance enrichment method was used. Two PPALs employed each of the two cooling methods. The objectives of this study are: (1) to analyze the feasibility of saving electric-energy by exchanging air with outdoor cool air in comparison with using only the heat pump; (2) to examine whether air exchanging would impact the

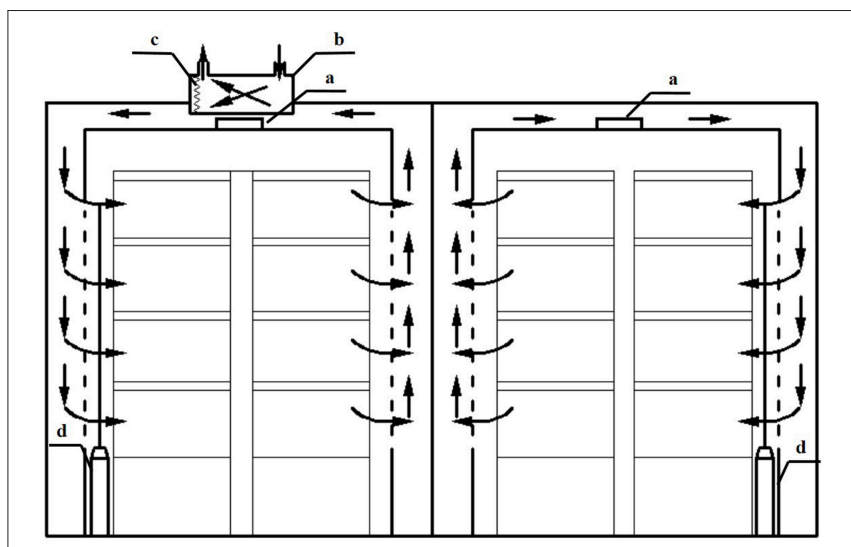

FIGURE 1 | Schematic diagram of the plant factories used in the experiment. a: heat pump installed inside the PPAL; b: air exchanger installed inside the ceiling of the PPAL; c: air filter; $\mathrm{d}: \mathrm{CO}_{2}$ gas cylinder.

amount of supplied $\mathrm{CO}_{2}$ if null $\mathrm{CO}_{2}$ balance enrichment method is used; and (3) to determine whether introducing outdoor air would have any negative effects on plant growth.

\section{MATERIALS AND METHODS}

\section{Plant Production System with Artificial Light (PPAL)}

Two PPALs were used in this experiment. Each PPAL with a volume of $11.7 \mathrm{~m}^{3}$ (2.2 $\mathrm{m}$ wide, $2.8 \mathrm{~m}$ long and $1.9 \mathrm{~m}$ high) was built in 2012 and located in China Academy of Agricultural Sciences, Beijing. The Plan view of the PPALs is shown in Figure 1. Each PPAL was installed two plant cultivation modules with three layers. The dimension of the plant cultivation modules was $2.1 \times 0.7 \times 1.8 \mathrm{~m}$. Each layer was equipped with a cultivation bed $(2.0 \mathrm{~m}$ long, $0.6 \mathrm{~m}$ wide, and $0.06 \mathrm{~m}$ deep) and fluorescent lamps (24 W, NVC-YZ24-T5, Guangdong, China), $0.4 \mathrm{~m}$ above the cultivation bed. In the culture beds, nutrient solution was circulated continuously by water pumps. Styrofoam boards were floated on the nutrient solution to support lettuce plants. Each PPAL was equipped with an air source heat pump for cooling (cooling capacity: $3.2 \mathrm{~kW}$, FTXN32KV2C, Daikin, Industries. Ltd, Japan) and a $\mathrm{CO}_{2}$ gas cylinder for $\mathrm{CO}_{2}$ enrichment. On the ceiling of the experimental PPAL $\left(\mathrm{PPAL}_{\mathrm{e}}\right)$, one air exchanger (capacity: $180 \mathrm{~W}$, air flow rate: $250 \mathrm{~m}^{3} \cdot \mathrm{h}^{-1}$, FY25LD2C, Guangdong, China) and an air filter (FY-BFG062C, Panasonic Ecology Systems Guangdong Co., Ltd) was installed for exchanging indoor warm and humid air with outdoor cold and dry air. Another PPAL $\left(\mathrm{PPAL}_{\mathrm{c}}\right)$ with only the heat pump was used as reference.

\section{Plant Materials and Growth Conditions}

Lettuce plants (Lactuca sativa var.) were grown in the PPALs during the experiment. Lettuce seeds were sown in a plastic tray under LED light $\left(80 \mu \mathrm{mol} \cdot \mathrm{m}^{-2} \cdot \mathrm{s}^{-1}\right)$ and irrigated with tap water once a day. Fifteen days after sowing, uniform seedlings were transplanted into the styrofoam boards with a density of 25 plants $\cdot \mathrm{m}^{-2}$ and grown hydroponically using modified 


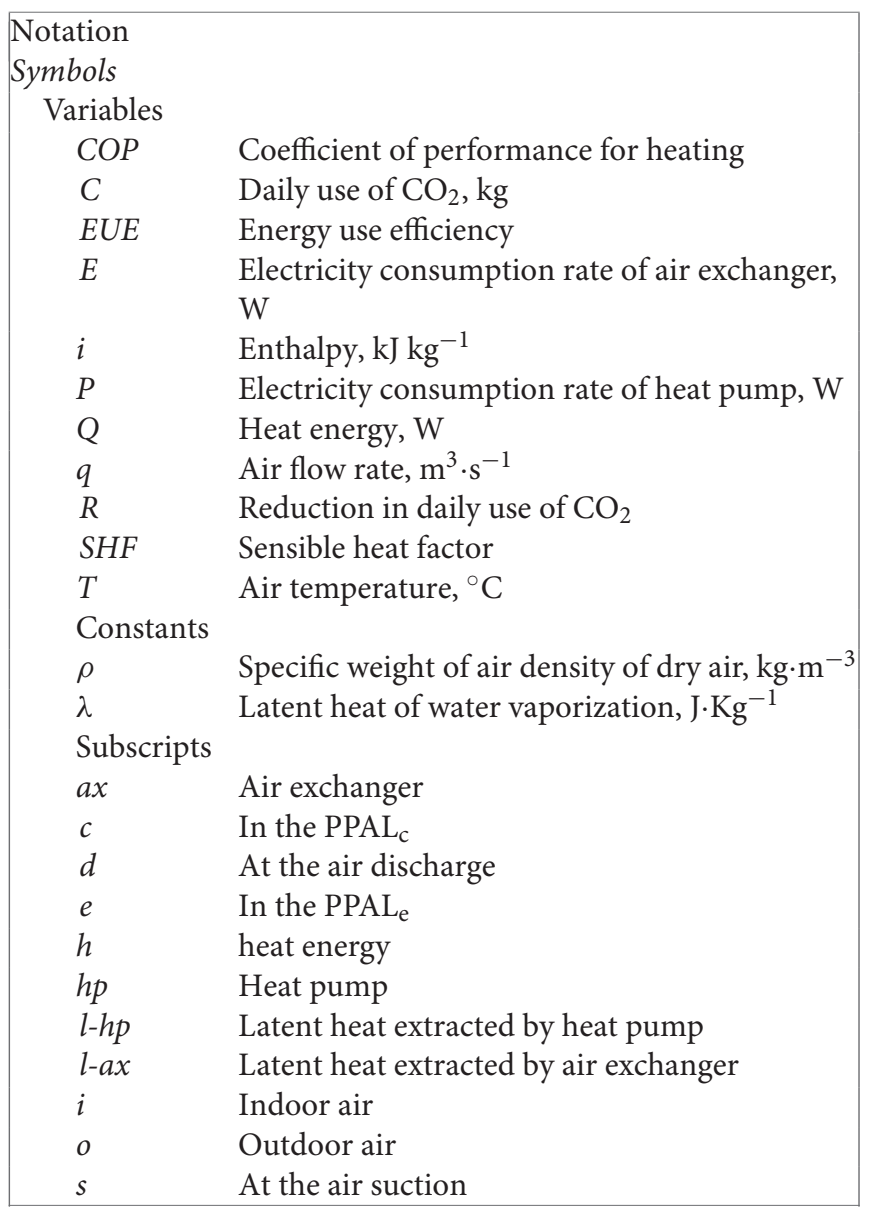

Hoagland's solution, whose chemical composition was as follows $\left(\mathrm{mg} \cdot \mathrm{L}^{-1}\right): \mathrm{Ca}\left(\mathrm{NO}_{3}\right)_{2} \cdot 4 \mathrm{H}_{2} \mathrm{O}, 945 ; \mathrm{KNO}_{3}, 607 ; \mathrm{NH}_{4} \mathrm{H}_{2} \mathrm{PO}_{4}$, 115; $\mathrm{MgSO}_{4} \cdot 7 \mathrm{H}_{2} \mathrm{O}, 495 ; \mathrm{Na}_{2} \mathrm{Fe}$-EDTA, 30; $\mathrm{MnSO}_{4} \cdot \mathrm{H}_{2} \mathrm{O}, 1.61$; $\mathrm{CuSO}_{4} \cdot 5 \mathrm{H}_{2} \mathrm{O}, 0.08 ; \mathrm{ZnSO}_{4} \cdot 7 \mathrm{H}_{2} \mathrm{O}, 0.22 ;(\mathrm{NH} 4)_{6} \mathrm{Mo}_{7} \mathrm{O}_{24} \cdot 4 \mathrm{H}_{2} \mathrm{O}$, $0.02, \mathrm{H}_{2} \mathrm{BO}_{3}, 2.86$. The nutrient solution was renewed once a week and the electrical conductivity of the solution was adjusted to $2.0 \mathrm{dS} \cdot \mathrm{m}^{-1}$. Nutrient solution $\mathrm{pH}$ was maintained at 6.0 to 6.5. During the experiment, indoor air temperature was set at 25 and $20^{\circ} \mathrm{C}$ during photoperiod and dark period, respectively. Photosynthetic photon flux $(P P F)$ measured at a distance of $10 \mathrm{~cm}$ up from cultivation beds was $150 \mu \mathrm{mol} \cdot \mathrm{m}^{-2} \cdot \mathrm{s}^{-1}$ with a photoperiod of $12 \mathrm{~h} \cdot \mathrm{d}^{-1}$ (dark period: 21:00-09:00). Indoor $\mathrm{CO}_{2}$ concentration was always kept at the same as outdoor level.

\section{Experimental Setup}

In the $\mathrm{PPAL}_{\mathrm{e}}$, indoor air temperature $\left(T_{i}\right)$ was allowed to maintain at around the set point of 25 and $20^{\circ} \mathrm{C}$ during photoperiod and dark period, respectively, within the range from $T_{l}$ to $T_{h}$, where the $T_{l}$ was the low air temperature set point and $T_{h}$ was the high temperature set point. $T_{l}$ was 23 and $18^{\circ} \mathrm{C}$ during photoperiod and dark period, respectively; $T_{h}$ was 27 and $22^{\circ} \mathrm{C}$ during photoperiod and dark period, respectively. The air temperature dead band was configured to avoid frequent ON/OFF operation of the air exchanger and heat pump for cooling. $T_{i}$ in the PPAL $\mathrm{L}_{\mathrm{e}}$ was controlled by the air exchanger aided by the heat pump. When the outdoor air temperature $\left(T_{o}\right)$ was lower than $T_{l}$, and $T_{i}$ was higher than the temperature set point, the outdoor cold and dry air was introduced by the air exchanger for cooling. If $T_{i}$ went above $T_{h}$, the air exchanger was turned off, and the heat pump started to operate for cooling until $T_{i}$ decreased to the set temperature. If $T_{i}$ dropped below $T_{l}$, the air exchanger was also automatically turned off. If $T_{o}$ was higher than $T_{h}$, the heat pump was operated for cooling. In the PPAL $L_{c}$, only the heat pump was used to maintain the indoor air temperature at the set point of 25 and $20^{\circ} \mathrm{C}$ during photoperiod and dark period, respectively.

During photoperiod, a null $\mathrm{CO}_{2}$ balance enrichment method was employed in both PPALs. The $\mathrm{CO}_{2}$ supply system consisted of a $\mathrm{CO}_{2}$ gas cylinder, an electronic mass flow meter (CMS 0020/0050), $\mathrm{CO}_{2}$ distribution perforated plastic tubes $(3 \mathrm{~mm}$, polyethylene) network. The $\mathrm{CO}_{2}$ distribution plastic tubes reached out to each layer to distribute $\mathrm{CO}_{2}$ uniformly. In the $\mathrm{PPAL}_{e}, \mathrm{CO}_{2}$ was supplemented by outdoor air when the air exchanger was operating. But whenever the indoor $\mathrm{CO}_{2}$ concentration was $50 \mu \mathrm{mol} \cdot \mathrm{mol}^{-1}$ lower than outdoor due to reduced operation of air exchanger, the $\mathrm{CO}_{2}$ from the gas cylinder was released into the $\mathrm{PPAL}_{e}$. While in the $\mathrm{PPAL}_{\mathrm{c}}$, only the $\mathrm{CO}_{2}$ from the gas cylinder was used to keep the indoor $\mathrm{CO}_{2}$ concentration at the same as outdoor level. The experiment was conducted from November 13th to December 18th in 2014.

\section{Calculations}

\section{Coefficient Of Performance (COP) for Cooling of the Heat Pump}

COP of the heat pump for cooling a PPAL was defined as:

$$
C O P=\frac{Q_{h p}}{P}
$$

where $Q_{h p}$ : heat energy removed rate by the heat pump (W), $P$ : electric-energy consumption rate of the heat pump (W).

Heat energy removed rate by the heat pump was calculated by the general known equation:

$$
Q_{h p}=q \cdot \rho \cdot\left(i_{s}-i_{d}\right)
$$

where $q$ : air flow rate of the heat pump $\left(\mathrm{m}^{3} \cdot \mathrm{s}^{-1}\right) ; \rho$ : density of dry air ( $\mathrm{kg}$ (D.A.). $\left.\mathrm{m}^{-3}\right) ; i_{s}$ : enthalpy at the air suction of the internal unit of the heat pump (J. $\mathrm{kg}^{-1}$ (D.A.)); $i_{d}$ : enthalpy at the discharge ports of the internal unit of the heat pump (J. $\mathrm{kg}^{-1}$ (D.A.)).

The sensible heat factor of the heat pump $\left(S H F_{h p}\right)$ was defined as:

$$
S H F_{h p}=1-\frac{Q_{l-h p}}{Q_{h p}}
$$

where

$$
Q_{l-h p}=\lambda \cdot q \cdot \rho \cdot\left(x_{s}-x_{d}\right)
$$

is the latent heat load $(\mathrm{W})$, with $\lambda$ : latent heat of water vaporization $\left(2.5 \times 10^{6} \mathrm{~J} \cdot \mathrm{kg}^{-1}\right.$ at $20^{\circ} \mathrm{C}$; ASHRAE, 2001); $x_{s}, x_{d}$ : absolute humidity at the air suction and discharge ports of the internal unit of the heat pump $\left(\mathrm{kg} \cdot \mathrm{kg}^{-1}\right.$ (D.A.)). 


\section{Electric-Energy Use Efficiency of the Air Exchanger}

The electric-energy use efficiency of air exchanger (EUE) was defined as:

$$
E U E=\frac{Q_{a x}}{E}
$$

where $Q_{a x}$ : heat energy removed rate by the air exchanger (W), E: electricity consumption rate of the air exchanger (W).

Heat energy removed rate by the air exchanger was calculated similar to Equation (2):

$$
Q_{a x}=q \cdot \rho \cdot\left(i_{i}-i_{o}\right)
$$

where $i_{i}$ : enthalpy of the indoor air $\left(\mathrm{J} \cdot \mathrm{kg}^{-1}\right.$ (D.A.)); $i_{o}$ : enthalpy of the outdoor $\operatorname{air}\left(J \cdot \mathrm{kg}^{-1}\right.$ (D.A.)).

The sensible heat factor of air exchanger $\left(S H F_{a x}\right)$ can be estimated by:

$$
S H F_{a x}=1-\frac{Q_{l-a x}}{Q_{a x}}
$$

Where

$$
Q_{l-a x}=\lambda \cdot q \cdot \rho \cdot\left(x_{i}-x_{o}\right)
$$

is the latent heat load (W); $x_{i}$ : absolute humidity of the air expelled from the PPAL $\left(\mathrm{kg} \cdot \mathrm{kg}^{-1}\right.$ (D.A.)); $x_{o}$ : absolute humidity of the outdoor air entering the PPAL $\left(\mathrm{kg} \cdot \mathrm{kg}^{-1}\right.$ (D.A.)).

\section{Reduction in the Amount of Supplied $\mathrm{CO}_{2}$}

The reduction in the amount of supplied $\mathrm{CO}_{2}(\mathrm{R})$ was calculated by:

$$
R=C_{c}-C_{e}
$$

Where $C_{c}$ : daily amount of $\mathrm{CO}_{2}$ supplemented to the PPALc $(\mathrm{kg})$; and $C_{e}$ : daily amount of $\mathrm{CO}_{2}$ supplemented to the $\mathrm{PPAL}_{\mathrm{e}}(\mathrm{kg})$.

\section{Measurements \\ Environmental Conditions Inside and Outside the PPALs}

The inside air temperature and relative humidity of both the $\mathrm{PPAL}_{\mathrm{e}}$ and $\mathrm{PPAL}_{\mathrm{c}}$ were measured by sensors (TR-72WF, T\&D, Co. Japan; precision: air temperature $\pm 0.3^{\circ} \mathrm{C}$, relative humidity $\pm 3 \%$ ). Three sensors were set at a height of $1.5 \mathrm{~m}$ from the ground at three measuring points in the middle of each PPAL. The air temperature and relative humidity at the air suction and air discharge ports of the internal unit of each heat pump were measured using sensors (TR-72WF, T\&D, Co. Japan; precision: air temperature $\pm 0.3^{\circ} \mathrm{C}$, relative humidity $\pm 3 \%$ ). Vapor pressure deficit (VPD) was determined from the measurements of the air temperature and relative humidity, as the method described in Prenger and Ling (2001). The inside $\mathrm{CO}_{2}$ concentration was measured by an infrared type $\mathrm{CO}_{2}$ analyzer (GMT 222, Vaisala Oyj, Helsinki, Finland). The $\mathrm{CO}_{2}$ analyzer was set at $1.5 \mathrm{~m}$ above floor level in the middle of each PPAL. All the above data were automatically recorded every minute with a wireless data collection system. The air flow rate at the air discharge port of the internal unit of each heat pump was measured manually once every second using an air flow meter (Model 6533, Kanomax, Japan).

The outdoor air temperature, relative humidity (TR-72WF, $\mathrm{T} \& \mathrm{D}$, Co. Japan; precision: air temperature $\pm 0.3^{\circ} \mathrm{C}$, relative humidity $\pm 3 \%$ ) and $\mathrm{CO}_{2}$ concentration(GMT 222, Vaisala Oyj, Helsinki, Finland) were recorded every minute in a small weather station $5 \mathrm{~m}$ away from the experimental PPAL. All the data were recorded every minute.

\section{Energy Consumption in Both PPALs}

The electric-energy consumption rates of heat pumps and air exchanger were measured by wattmeters (KWm8115, Panasonic Electric Works, Japan) and recorded every minute.

\section{Daily Use of $\mathrm{CO}_{2}$ Supplemented to Both PPALs}

Daily use of $\mathrm{CO}_{2}$ supplemented to both PPALs were determined from continuously measurement of the weight of the $\mathrm{CO}_{2}$ cylinders, using electronic scales (FZ-TCS50, Julin, Instruments, Co., Xiamen, China).

\section{Measurement of Lettuce Plant Growth and Chlorophyll Concentration}

At the 25 and 35 days after transplanting, lettuce plants were randomly sampled to measure their growth. Fifteen plants from each PPAL were harvested each time to measure their fresh weights. Dry weights were measured after being dried at $80^{\circ} \mathrm{C}$ for $72 \mathrm{~h}$.

Samples were excised from the leaves of 10 plants at a similar position for each treatment. Leaves were weighed out in $0.1-0.2 \mathrm{~g}$ (fresh weight). The extractions were performed using $10 \mathrm{ml}(\mathrm{V})$ of $80 \%$ acetone until the leaf turned white. The optical density was measured with UV-1800 spectrophotometer (Shimadzu, Japan) at $663 \mathrm{~nm}(\mathrm{OD} 663)$ and at $645 \mathrm{~nm}$ (OD645) for chlorophyll a (Chl a) and chlorophyll b (Chl b). The chlorophyll concentrations (Chl) were determined as the method described in Lichtenthaler and Wellburn (1983).

\section{Statistical analysis}

Statistical differences among the treatments were analyzed by the least significant difference (LSD) test $(p<0.05)$ when analysis of variance (ANOVA) by SPSS software (SPSS for Windows, SPSS Inc., USA) indicated treatment significance.

\section{RESULTS}

\section{Energy Use Efficiencies of Air Exchanger and Heat Pumps}

Both the EUE of air exchanger and the COP of heat pumps for cooling increased with the increase in air temperature difference between indoor and outdoor. When the air temperature difference between indoor and outdoor ranged from 20.2 to $30.0^{\circ} \mathrm{C}$, the EUE of the air exchanger for cooling the $\mathrm{PPAL}_{\mathrm{e}}$ ranged from 18.6 to 32.9 with an average of 25.6, the COP of the heat pump in the $\mathrm{PPAL}_{\mathrm{e}}$ ranged from 4.2 to 18.2 with an average of 9.0, and the COP of the heat pump in the $\mathrm{PPAL}_{\mathrm{c}}$ ranged from 1.6 to 16.8 with an average of 7.5 (Figure 2). The average EUE of 


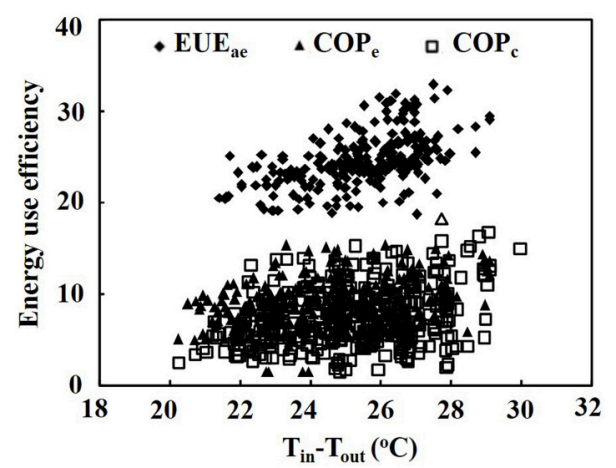

FIGURE 2 | Energy use efficiency of the air exchanger and heat pumps as affected by the air temperature difference between indoor and outdoor. EUE, energy use efficiency of the air exchanger; $\mathrm{COP}_{e}$, energy use efficiency of the heat pump in the PPALe; $\mathrm{COP}_{\mathrm{C}}$, energy use efficiency of the heat pump in the PPAL .

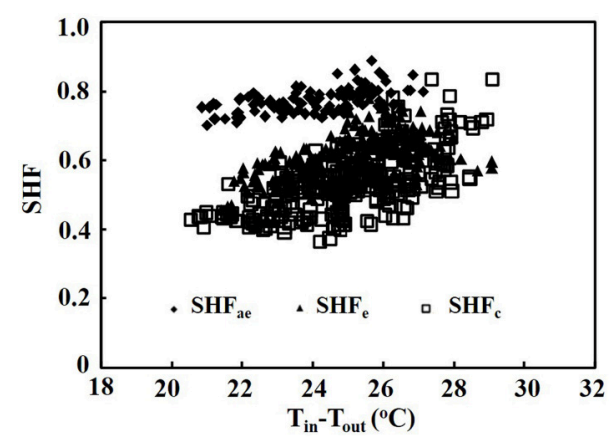

FIGURE 3 | Sensible heat factor (SHF) of the air exchanger and heat pumps as affected by the air temperature difference between indoor and outdoor. $\mathrm{SHF}_{\mathrm{ae}}$, sensible heat factor of the air exchanger; $\mathrm{SHF}_{\mathrm{e}}$, sensible heat factor of the heat pump in the PPAL $L_{e} \mathrm{SHF}_{\mathrm{C}}$, sensible heat factor of the heat pump in the PPAL .

air exchanger was 2.8 and 3.4 times greater than the average COP of the heat pumps in the $\mathrm{PPAL}_{\mathrm{e}}$ and $\mathrm{PPAL}_{\mathrm{c}}$, respectively.

\section{SHF of Air Exchanger and Heat Pumps}

When the air temperature difference between indoor and outdoor ranged from 20.2 to $30.0^{\circ} \mathrm{C}$, the SHF of the air exchanger ranged from 0.7 to 0.9 , the $\mathrm{SHF}$ of the heat pump in the $\mathrm{PPAL}_{\mathrm{e}}$ ranged from 0.5 to 0.7 , while the SHF of the heat pump in the $\mathrm{PPAL}_{\mathrm{c}}$ ranged from 0.4 to 0.8 (Figure 3 ).

\section{Electric-Energy Consumption of Air Exchanger and Heat Pumps}

When the air temperature difference between indoor and outdoor ranged from 20.2 to $35.7^{\circ} \mathrm{C}$, the hourly electric-energy consumption of the air exchanger ranged from $0.11 \mathrm{MJ}$ to 0.58 $\mathrm{MJ}$, while that of the heat pump in the $\mathrm{PPAL}_{\mathrm{e}}$ ranged from 0.32 to $0.04 \mathrm{MJ}$, and that of the heat pump in the $\mathrm{PPAL}_{\mathrm{c}}$ ranged from 0.86 to $0.47 \mathrm{MJ}$ (Figure 4). The hourly electric-energy consumption in the $\mathrm{PPAL}_{\mathrm{e}}$ was $15.8-73.7 \%$ lower than that in the $\mathrm{PPAL}_{\mathrm{c}}$.

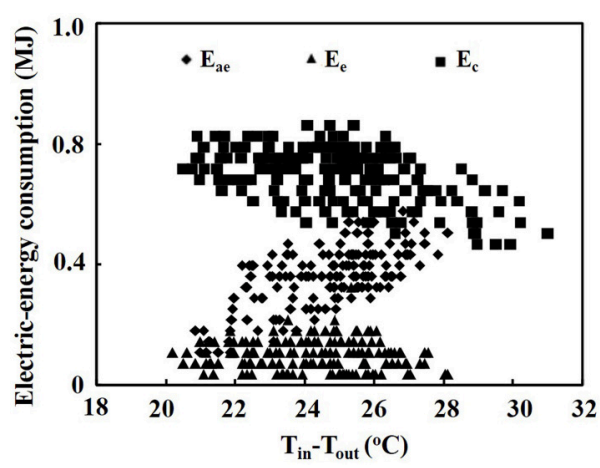

FIGURE 4 | Electric-energy consumption of the air exchanger and heat pumps as affected by the air temperature difference between indoor and outdoor. $E_{a e}$, electric-energy consumption of the air exchanger; $E_{e}$, electric-energy consumption of the heat pump in the PPALe; $E_{C}$, electric-energy consumption of the heat pump in the PPAL .

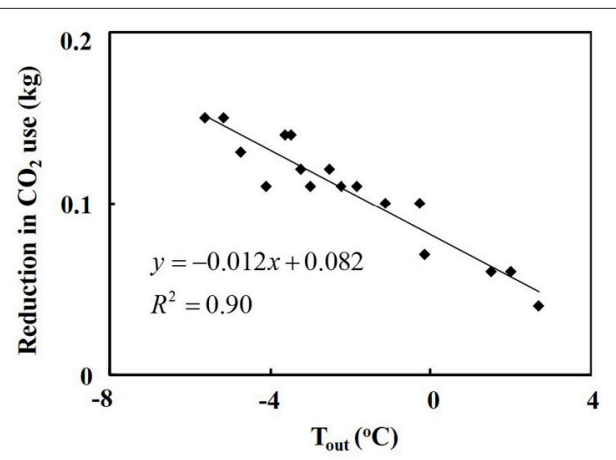

FIGURE 5 | Reduction of daily $\mathrm{CO}_{2}$ supplied in the PPAL $\mathrm{L}_{\mathrm{e}}$ compared with that in the PPAL $c$ as affected by outdoor air temperature.

\section{Reduction in the Use of Supplemental $\mathrm{CO}_{2}$}

The $\mathrm{PPAL}_{\mathrm{e}}$ required $0.04-0.15 \mathrm{~kg}$ less $\mathrm{CO}_{2}$ per day to replenish the $\mathrm{CO}_{2}$ depletion than the $\mathrm{PPAL}_{\mathrm{c}}$, when the daily average outdoor air temperature ranged from -5.6 to $2.7^{\circ} \mathrm{C}$ (Figure 5).

\section{Environmental Conditions in Both PPALS}

The air temperature inside both PPALs could be controlled within the acceptable ranges $\left(23\right.$ to $27^{\circ} \mathrm{C}$ during photoperiod and 18 to $22^{\circ} \mathrm{C}$ during dark period, respectively). The air temperature inside the $\mathrm{PPAL}_{\mathrm{e}}$ was lower than that of $\mathrm{PPAL}_{\mathrm{c}}$ with a highest different value of $4.7^{\circ} \mathrm{C}$. The high fluctuation of air temperature inside the $\mathrm{PPAL}_{\mathrm{e}}$ was observed especially during lower outdoor air temperature (Figure 6A).

The VPD in the PPAL $\mathrm{e}_{\mathrm{e}}$ ranged from 0.5 to $1.8 \mathrm{kPa}$ during photoperiod and from 0.2 to $1.0 \mathrm{kPa}$ during dark period. While the VPD in the $\mathrm{PPAL}_{\mathrm{c}}$ ranged from 0.2 to $1.8 \mathrm{kPa}$ during photoperiod and from 0.2 to $1.0 \mathrm{kPa}$ during dark period (Figure 6B).

$\mathrm{CO}_{2}$ concentration during photoperiod in both PPALs could be maintained at around outdoor level in this experiment. Average $\mathrm{CO}_{2}$ concentration during photoperiod 


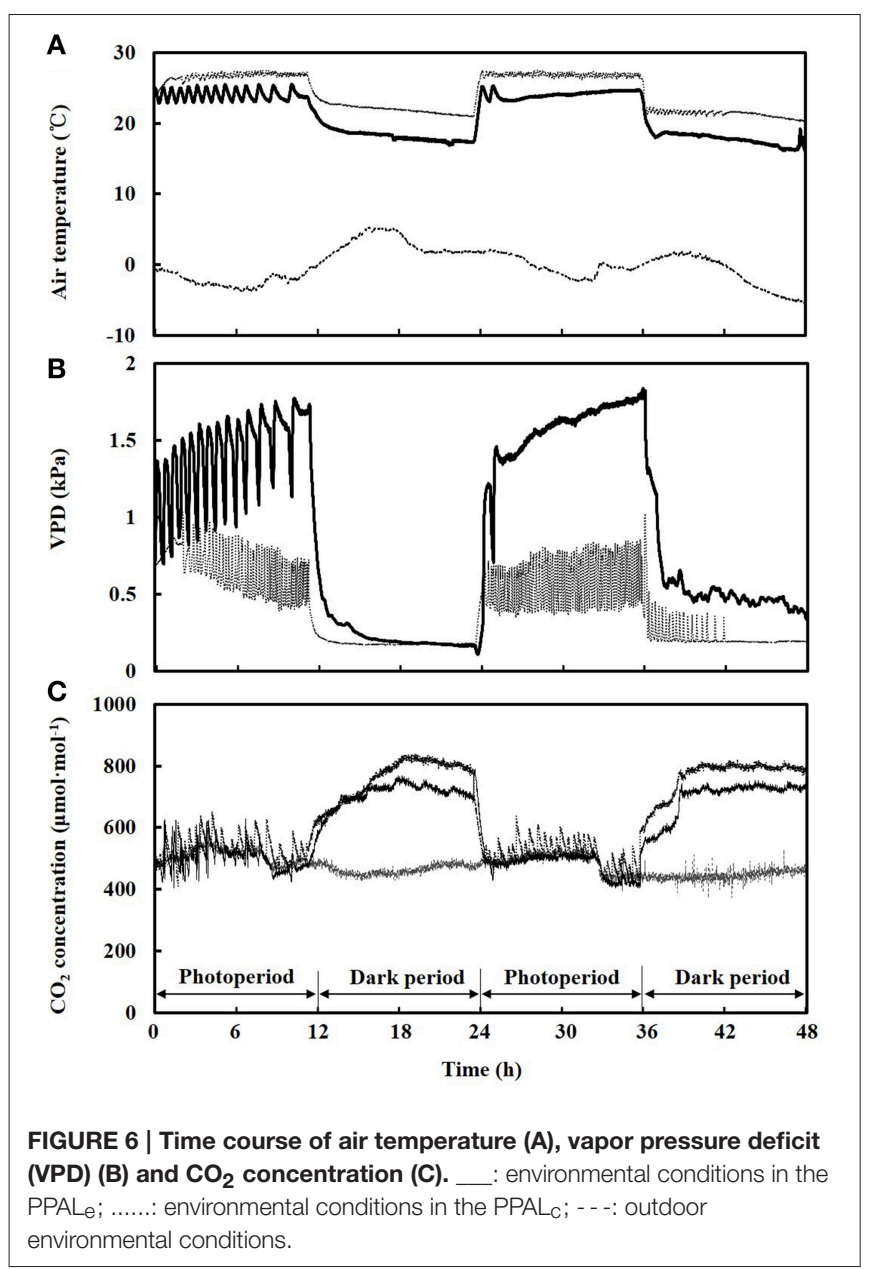

was 493 and $510 \mu \mathrm{mol} \mathrm{mol}{ }^{-1}$ in the $\mathrm{PPAL}_{\mathrm{e}}$ and $\mathrm{PPAL}_{\mathrm{c}}$, respectively, while the average outdoor $\mathrm{CO}_{2}$ concentration was $498 \mu \mathrm{mol} \mathrm{mol} \mathrm{m}^{-1}$ (Figure 6C). During dark period, $\mathrm{CO}_{2}$ concentration in the $\mathrm{PPAL}_{\mathrm{e}}$ increased from 472 to $769 \mu \mathrm{mol} \cdot \mathrm{mol}^{-1}$, while that in the PPAL $\mathrm{L}_{\mathrm{c}}$ increased from 522 to $841 \mu \mathrm{mol} \cdot \mathrm{mol}^{-1} \cdot \mathrm{CO}_{2}$ concentration during dark period was lower in the $\mathrm{PPAL}_{\mathrm{e}}$ than that in the $\mathrm{PPAL}_{\mathrm{c}}$ during this experiment.

\section{Lettuce Growth in Both PPALS}

The growth images of lettuce on DAT15 and DAT30 in PPALe and PPALc were showed in Figures 7A,B, respectively. Figure 8 presents the fresh and dry weights measured at 25 and 35 days after transplanting. No significant differences of fresh or dry weight of lettuce plants were found between the two PPALs. By calculating from data used in Figure 8, the ratio of shoot fresh weight to dry weight in $\mathrm{PPAL}_{e}$ and $\mathrm{PPAL}_{\mathrm{c}}$ were 16.4 and $16.3 \mathrm{~g} \cdot \mathrm{g}^{-1}$, respectively, while the ratio of root fresh weight to dry weight in $\mathrm{PPAL}_{e}$ and $\mathrm{PPAL}_{\mathrm{c}}$ were 29.1 and $32.3 \mathrm{~g} \cdot \mathrm{g}^{-1}$, respectively. There were no significant differences between the two PPALs. Photosynthetic pigments of lettuce plants in both PPALs also showed no significant difference (Figure 9).

\section{DISCUSSION}

\section{Feasibility of Saving Electric-Energy by Air Exchanging with Outdoor Air for Cooling}

In the present experiment, the high EUE of air exchanger indicates that air exchanger with a low capacity is more energyefficient for cooling in a PPAL than the heat pump with a high capacity under the experimental conditions. In the present experiment, both the EUE of air exchanger and the COP of heat pumps for cooling increased with decreasing outdoor air temperature when the indoor air temperature could be maintained at around the set point, which agrees with previous reports (e.g., Tong et al., 2013). The reason of higher EUE of the air exchanger in comparison with the COP of the heat pumps probably was that the outdoor air with low temperature and humidity was introduced into indoor directly by using air exchanger with low capacity. The COP of the heat pump in the $\mathrm{PPAL}_{\mathrm{e}}$ was slightly higher than the COP of heat pump in the $\mathrm{PPAL}_{\mathcal{c}}$, probably because the operation time of the heat pump in the $\mathrm{PPAL}_{e}$ in low heat load was reduced by introducing outdoor cold air.

In Figure 2, the scattered data for EUE of the air exchanger and COP of both heat pumps were probably because the EUE and $\mathrm{COP}$ were not only affected by the air temperature but also affected by the relative humidity of indoor and outdoor air (Tong et al., 2010).Thus, the air exchanger and heat pump not only extracted sensible heat but also latent heat from the PPALs. The SHF value represents the ratio of the sensible heat energy to the total heat energy removed from the PPALs by air exchanger and heat pumps. The higher SHF value of the air exchanger indicated that mainly sensible heat contributed to the total heat energy extracted from the PPAL $L_{e}$, because introducing outdoor dry air reduced indoor-outdoor relative humidity difference. The SHF of the heat pump in the $\mathrm{PPAL}_{\mathrm{c}}$ was slightly lower than that in the $\mathrm{PPAL}_{\mathrm{e}}$ (Figure 3), probably because the higher indoor relative humidity increased the ratio of latent heat energy to the total heat energy extracted from the $\mathrm{PAL}_{\mathrm{c}}$.

\section{Saving Electric-Energy by Using the Air Exchanger}

Hourly electric-energy consumption of the air exchanger and heat pumps as affected by air temperature difference between indoor and outdoor is shown in Figure 4. The electric-energy consumption of the heat pump both in the $\mathrm{PPAL}_{\mathrm{c}}$ and the $\mathrm{PPAL}_{\mathrm{e}}$ decreased with increasing air temperature difference between indoor and outdoor due to the increased COP. The hourly electric-energy consumption of the heat pump in the $\mathrm{PPAL}_{e}$ was much lower than that of the heat pump in the PPAL $\mathrm{P}_{\mathrm{c}}$. Compared with the heat pump in the PPAL $L_{c}$, saving-energy of the heat pump in the PPAL became more pronounced with increasing air temperature difference between indoor and outdoor. The above results indicated that the operation time of the heat pump in the $\mathrm{PPAL}_{e}$ was significantly shortened, particularly under large air temperature difference. The hourly electricenergy consumption of air exchanger increased with increasing air temperature difference between indoor and outdoor although the EUE increased. This was because with decreasing outdoor air 


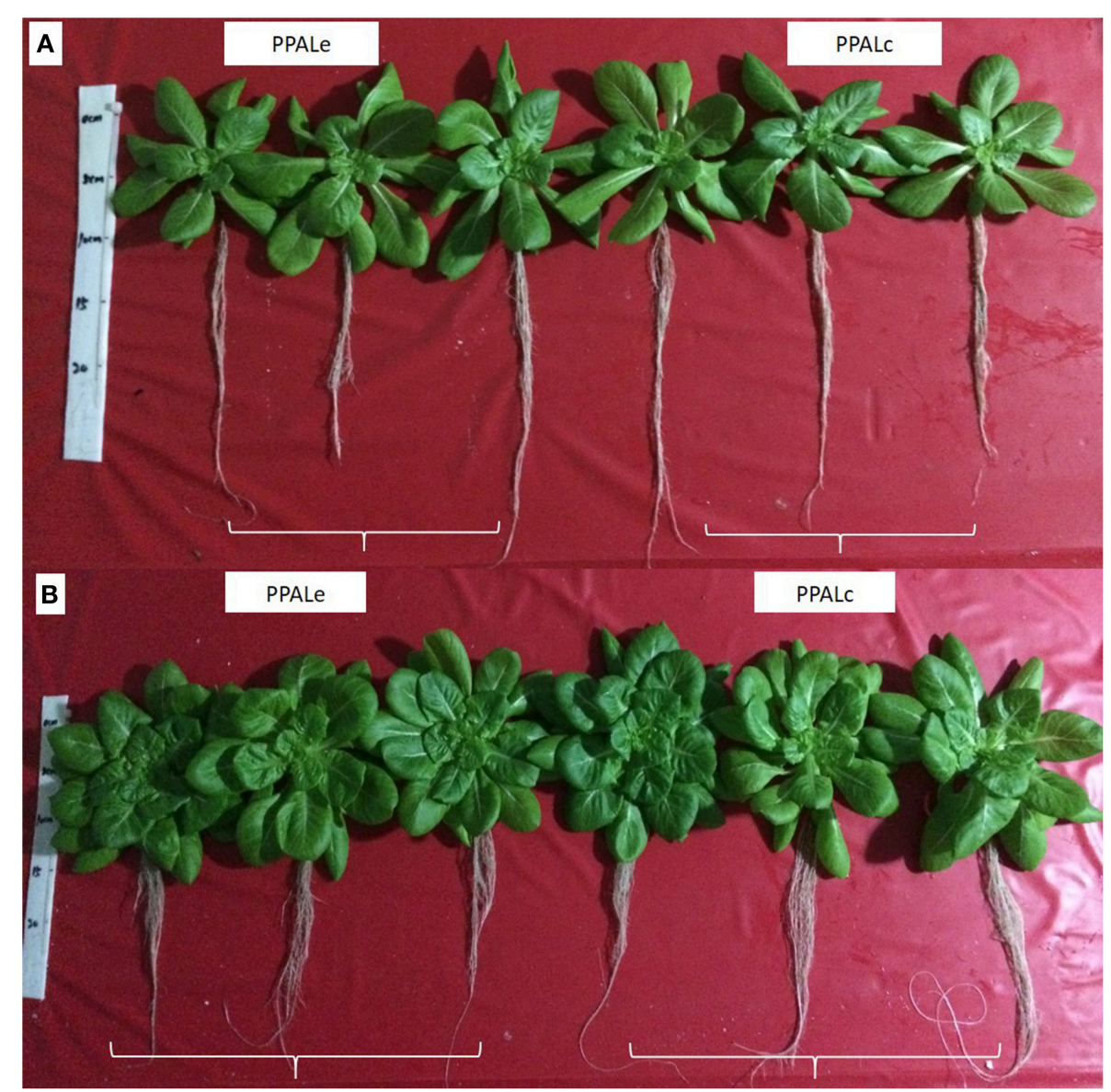

FIGURE 7 | Growth images of lettuce on DAT15 (A) and DAT30 (B) in the PPAL ${ }_{e}$ and PPAL .

temperature, operation time of the air exchanger increased since the indoor air temperature could be controlled at the set point using only air exchanger for cooling.

\section{Reduction in the Use of Supplemental $\mathbf{C O}_{2}$}

In the experiment, to avoid high $\mathrm{CO}_{2}$ depletion and low $\mathrm{CO}_{2}$ utilization efficiency, $\mathrm{CO}_{2}$ concentration was replenished to keep the concentration at outside level. The reduction in daily supply of $\mathrm{CO}_{2}$ in the $\mathrm{PPAL}_{\mathrm{e}}$ was because $\mathrm{CO}_{2}$ gas from outdoor air was supplied to the indoor air when the air exchanger was used and the pure $\mathrm{CO}_{2}$ was used whenever the indoor $\mathrm{CO}_{2}$ concentration could not be kept at outside level, while in the $\mathrm{PPAL}_{\mathrm{c}}$, only pure $\mathrm{CO}_{2}$ was used to keep the indoor $\mathrm{CO}_{2}$ concentration at outside level. Increasing operation time of the air exchanger for introducing outdoor cold air could save $\mathrm{CO}_{2}$ supplied into a PPAL with the null $\mathrm{CO}_{2}$ balance enrichment method. With increasing outdoor air temperature the operation time of the air exchanger decreased as shown in Figure 4, so then more pure $\mathrm{CO}_{2}$ was needed.

\section{Environmental Conditions in Both PPALS}

Time course of air temperatures inside both PPALs shown in Figure 6A indicates that the air exchanger could be used for cooling in most of the time since the heat pump was operated for cooling when the indoor air temperature could not be controlled below 27 and $22^{\circ} \mathrm{C}$ during photoperiod and dark period, respectively. The fluctuation of air temperature inside the $\mathrm{PPAL}_{e}$ was because different control strategies of the air exchanger and heat pumps were employed in this experiment. Heat pumps employed a proportional-integral-derivative (PID) control method, while the air exchanger employed a simple ON/OFF control method.

$\mathrm{CO}_{2}$ concentration during photoperiod in both PPALs could be maintained at around outdoor level in this experiment, with the reasonable fluctuations of $\mathrm{CO}_{2}$ concentration in both PPALs caused by ON/OFF operation of the $\mathrm{CO}_{2}$ supplemental devices. To reduce the fluctuations in $\mathrm{CO}_{2}$ concentration, PID control method should be employed instead of ON/OFF control method. Compared to $\mathrm{CO}_{2}$ concentration in the $\mathrm{PPAL}_{\mathrm{c}}$, lower $\mathrm{CO}_{2}$ concentration in the $\mathrm{PPAL}_{\mathrm{e}}$ during dark period was caused by the amount of $\mathrm{CO}_{2}$ leakage increasing with increasing air exchange rate due to the operation of the air exchanger.

\section{Lettuce Growth in Both PPALS}

No significant differences of fresh/dry weights and photosynthetic pigments of lettuce plants were found despite of 


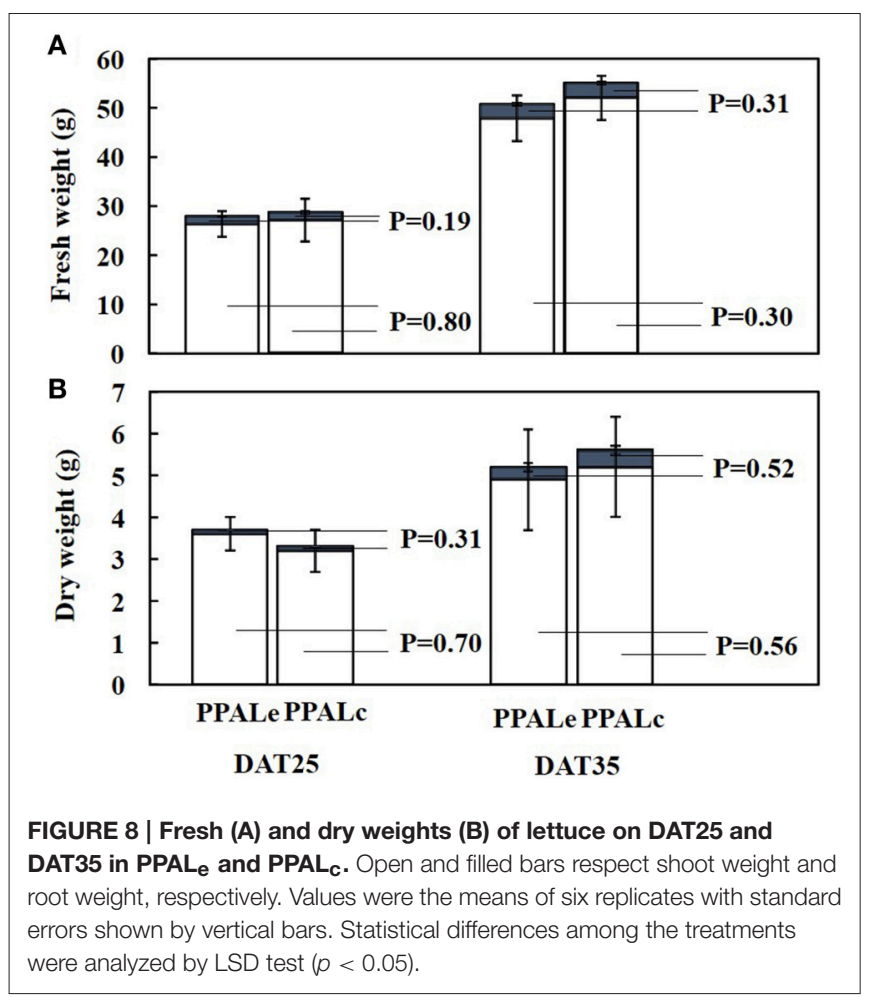

the differences in environmental conditions of the two PPALs. The air temperatures inside both PPALs were controlled within the optimum ranges recommended (Li et al., 2012; Chen et al., 2014; Tong and Yang, 2014), but the air temperature inside the $\mathrm{PPAL}_{\mathrm{c}}$ was slightly higher than that inside the PPAL $\mathrm{L}_{\mathrm{e}}$. High air temperature during photoperiod significantly improved plant growth, while high air temperature during dark period had adverse effects on plant growth because it would enhance dark respiration (Peet and Bartholomew, 1996; Morales et al., 2003).

A similar VPD ranged from 0.2 to $1.0 \mathrm{kPa}$ was observed in both PPALs during dark period. Grange and Hand (1987) quoted that a VPD in the range of $0.2-1.0 \mathrm{kPa}$ has little effect on the physiology and development of crops, while during photoperiod, the VPD in the PPAL $L_{e}$ was much higher than that in the $\mathrm{PPAL}_{\mathfrak{c}}$, because the very dry outdoor air was introduced into the $\mathrm{PPAL}_{\mathrm{e}}$ when the air exchanger was used. According to Hoffman (1979), an increase in VPD from 1 to $1.8 \mathrm{kPa}$ determines the major reduction in plant growth on several crops, and this could be probably due to the depression of photosynthesis ( $\mathrm{Xu}$ et al., 1991), related to the reduction of stomatal conductance (Grange and Hand, 1987). In contrast, some studies reported that low VPD positively affects dry matter accumulation and can also promote the incidence of calcium related physiological disorders in leaves (Janse and Welles, 1984; Holder and Cockshull, 1990; Kreij, 1996; Dorais et al., 2004).

The average $\mathrm{CO}_{2}$ concentration in both PPALs was maintained at approximately the same as outdoor level during photoperiod, although $\mathrm{CO}_{2}$ concentration in the $\mathrm{PPAL}_{\mathrm{C}}$ was slightly higher than that in the $\mathrm{PPAL}_{\mathrm{e}}$ during dark period. Based on above discussion, the lettuce plants growth in this experiment might be affected by different environmental

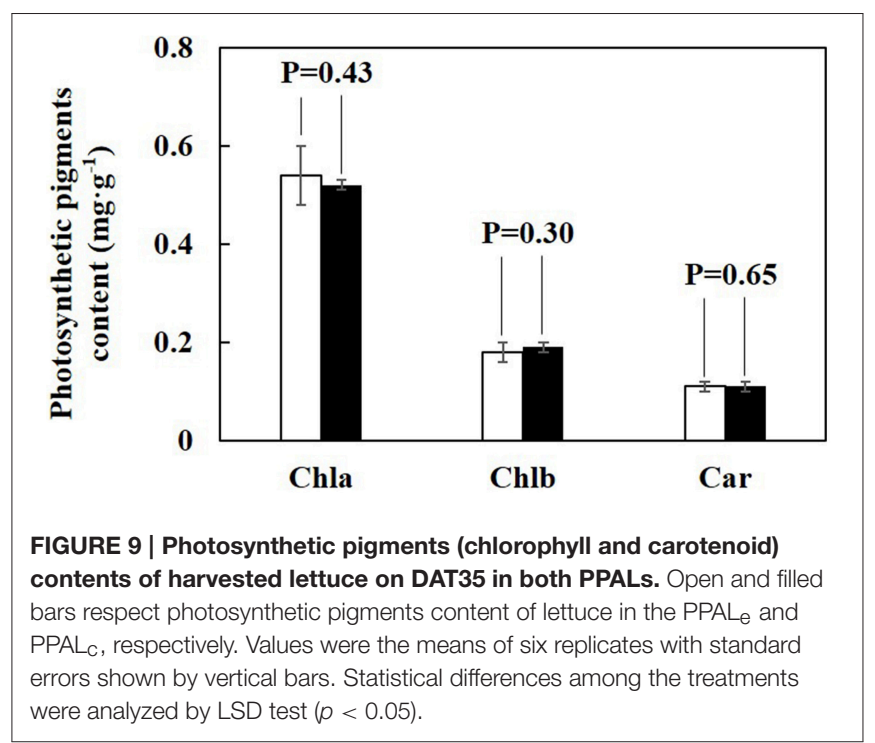

conditions, but positive effects because of higher air temperature during photoperiod were all offset by negative effects of higher air temperature during dark period and lower VPD in the $\mathrm{PPAL}_{\mathrm{c}}$.

\section{Economic Benefit Analysis of Introducing Outdoor Cold Air for Cooling Together with Null $\mathrm{CO}_{2}$ Balance Enrichment Method}

Costs for electric-energy consumed by the air exchanger and heat pumps were analyzed based on an industrial electricity cost of $0.81 \mathrm{RMB} \cdot \mathrm{kWh}^{-1}$ and data in Figure 4. Electric-energy cost for cooling in the PPAL $\mathrm{e}_{\mathrm{e}}$ ranged from 0.10 to $1.89 \mathrm{RMB} \cdot \mathrm{h}^{-1}$, with an average of $1.14 \mathrm{RMB} \cdot \mathrm{h}^{-1}$, while the electric-energy cost for cooling in the $\mathrm{PPAL}_{\mathrm{c}}$ ranged from 1.36 to $2.52 \mathrm{RMB} \cdot \mathrm{h}^{-1}$, with an average of $2.04 \mathrm{RMB} \cdot \mathrm{h}^{-1}$, when the air temperature difference between indoor and outdoor ranged from 20.2 to $35.7^{\circ} \mathrm{C}$. The above results indicated that about $0.9 \mathrm{RMB} \cdot \mathrm{h}^{-1}$ on average could be saved in the $\mathrm{PPAL}_{\mathrm{e}}$ than that in the $\mathrm{PPAL}_{\mathrm{c}}$ under the experimental conditions.

Cost for reduction in $\mathrm{CO}_{2}$ supplied in both PPALs was analyzed based on $\mathrm{CO}_{2}$ (purity of $99.9 \%$ ) cost of $0.71 \mathrm{RMB} \cdot \mathrm{kg}^{-1}$ and data in Figure 5. Reduction in $\mathrm{CO}_{2}$ cost ranged from 0.03 to $0.11 \mathrm{RMB} \cdot \mathrm{d}^{-1}$, with an average of $0.08 \mathrm{RMB} \cdot \mathrm{d}^{-1}$, when the daily average outdoor air temperature ranged from -5.6 to $2.7^{\circ} \mathrm{C}$.

As discussed in sections of "Saving electric-energy by using the air exchanger" and "Reduction in the use of supplemental $\mathrm{CO}_{2}$," the economic benefit of introducing outdoor cold air for cooling together with null $\mathrm{CO}_{2}$ balance enrichment method was significantly affected by the indoor and outdoor environmental conditions. Greater economic benefit can be achieved with increasing operation time of the air exchanger. Furthermore, the present experiment was conducted in a model PPAL with a small volume of $11.7 \mathrm{~m}^{3}$, while the volume of a commercial used PPAL is usually larger than $1000 \mathrm{~m}^{3}$. Thus, in a commercial used PPAL with a volume of $1000 \mathrm{~m}^{3}$, the saved electric energy and $\mathrm{CO}_{2}$ cost can be $76.92 \mathrm{RMB} \cdot \mathrm{h}^{-1}$ and 6.84 RMB $\cdot \mathrm{d}^{-1}$, respectively. However, the actual economic benefit in a commercial PPAL should be further confirmed in future researches. 


\section{CONCLUSION}

To reduce the electric-energy consumption for cooling in a PPAL, an air exchanger was employed aided by a heat pump for cooling by introducing outdoor air whenever the indoor air temperature was lower than outdoor air temperature. To avoid a high depletion of $\mathrm{CO}_{2}$ concentration and keep a high supplied $\mathrm{CO}_{2}$ utilization efficiency, a null $\mathrm{CO}_{2}$ balance enrichment method was used in this experiment. Experimental results showed that when the air temperature difference between indoor and outdoor ranged from 20.2 to $30.0^{\circ} \mathrm{C}$ : (1) the average EUE of the air exchanger was 2.8 and 3.4 times greater than the COP of the heat pumps in the $\mathrm{PPAL}_{e}$ and $\mathrm{PPAL}_{\mathfrak{c}}$, respectively; (2) the hourly electric-energy consumption in the $\mathrm{PPAL}_{\mathrm{e}}$ was reduced by $15.8-73.7 \%$ compared with that in the $\mathrm{PPAL}_{\mathcal{c}}$; (3) the daily use of supplemental $\mathrm{CO}_{2}$ in the $\mathrm{PPAL}_{\mathrm{e}}$ was greatly reduced from 0.15 to $0.04 \mathrm{~kg}$ compared with that in the $\mathrm{PPAL}_{\mathrm{c}}$. Operating the air exchanger did not

\section{REFERENCES}

ASHRAE (2001). 2001ASHRAE Fundamentals Handbook (SI). Atlanta, GA: American Society of Heating, Refrigerating and Air-conditioning Engineers, Inc.

Chen, X. L., Guo, W. Z., Xue, X. Z., Wang, L. C., and Qiao, X. J. (2014). Growth and quality responses of 'Green Oak Leaf' lettuce as affected by momochromic or mixed radiation provided by fluorescent lamp (FL) and lightemitting diode (LED). Sci. Hortic. 172, 168-175. doi: 10.1016/j.scienta.2014.0 4.009

Dorais, M., Demers, D. A., Papadopoulos, A. P., and Van Ieperen, W. (2004). Greenhouse tomato fruit cuticle cracking. Hortic. Rev. 30, 163-184. doi: $10.1002 / 9780470650837$

Fang, W. (2013). Quantification of performance in plant factory. Technol. Adv. Prot. Hortic. 64-71.

Grange, R. I., and Hand, D. W. (1987). A review of the effects of atmospheric humidity on the growth ofhorticultural crops. J. Hortic. Sci. 62, 125-134.

Hoffman, G. J. (1979). “Humidity," in Controlled Environment Guidelines for Plant Research, eds T. W. Tibbits and T. T. Kozlowski (London: Academic Press), 141-172.

Holder, R., and Cockshull, K. E. (1990). Effects of humidity on the growth and yield of glasshouse tomatoes. J. Hortic. Sci. 65, 31-39.

Janse, J., and Welles, G. W. H. (1984). Effects of energy saving measures on keeping quality of tomatoand cucumber fruits. Acta Hortic. 163, 261-269. doi: 10.17660/ActaHortic.1984.163.29

Kozai, T. (2009). Solar Assisted Plant Factory, 1st Edn. Tokyo: Ohmsha.

Kozai, T. (2012). Plant Factory with Artificial Light. Toyko: Ohmsha.

Kozai, T., Ohyama, K., and Chun, C. (2006). Commercialized closed systems with artificial lighting for plant production. Acta Hortic. 711, 61-70. doi: 10.17660/ActaHortic.2006.711.5

Kreij, C. (1996). Interactive effects of air humidity, calcium and phosphate on blossom-end rot, leaf deformation, production and nutrient content of tomato. J. Plant Nutr. 19, 361-377. doi: 10.1080/01904169609365127

Li, K., Yang, Q. C., Tong, Y. X., and Cheng, R. F. (2014). Using movable lightemitting diodes for electricity savings in a plant factory growing lettuce. Horttechnology 24, 546-553.

Li, M., Kozai, T., Ohyama, K., Shimamura, D., Gonda, K., and Sekiyama, T. (2012). $\mathrm{CO}_{2}$ balance of a commercial closed system with artificial lighting for producing lettuce plants. Hortscience 47, 1257-1260.

Lichtenthaler, H. K., and Wellburn, A. R. (1983). Determination of total carotenoids and chlorophylls $\mathrm{a}$ and $\mathrm{b}$ of leaf extracts in different affect the growth of lettuce. Overall, introducing cold air by air exchanger proved to be an effective cooling method for PPALs, however, auxiliary cooling devices are needed (such as heat pump) whenever air exchanger could not meet the cooling demand.

\section{AUTHOR CONTRIBUTIONS}

JW carried out the measurements, data analysis and drafted the manuscript. MX participated in part of measurements and data analysis. YT and QY made substantial guide about experiment design, and critically revised the manuscript.

\section{ACKNOWLEDGMENTS}

We are grateful for the financial support from the National High Technology Research and Development Plan of China (863 Project, grant No. 2013AA103007). solvents. Biochem. Soc. Trans. 603, 591-592. doi: 10.1042/bst01 10591

Morales, D., Rodriguez, P., Dell'Amico, J., Nicolas, E., Torrecillas, A., and SanchezBlanco, M. J. (2003). High-temperature preconditioning and thermal shock imposition affects water relations, gas exchange and root hydraulic conductivity in Tomato. Biol. Plant. 47, 6-12.

Nishimura, M., Kozai, T., Kubota, C., and Chun, C. (2001). Analysis of electric energy consumption and its cost for a closed-type transplant production system. J. Soc. High Technol. Agric. 13, 204-209. doi: 10.2525/jshita.1 3.204

Ohyama, K., Fujiwara, M., Kozai, T., and Chun, C. (2001).Consumption of electric energy and water for eggplant plug transplant production in a closedtype transplant production system. J. Soc. High Technol. Agric. 13, 1-6. doi: 10.2525/jshita.13.1

Peet, M. M., and Bartholomew, M. (1996). Effect of night temperature on pollen characteristics, growth and fruit set in tomato (Lycopersiconesculentum Mill). J. Am. Soc. Hortic. Sci. 121, 514-519.

Poulet, L., Massa, G. D., Morrow, R. C., Bourget, C. M., Wheeler, R. M., and Mitchell, C. A. (2014). Significant reduction in energy for plant-growth lighting in space using targeted LED lighting and spectral manipulation. Life Sci. Space Res. 2, 43-53. doi: 10.1016/j.lssr.2014.0 6.002

Prenger, J. J., and Ling, P. P. (2001). Greenhouse Condensation Control Understanding and Using Vapor Pressure Deficit (VPD). Available online at: http://citeseerx.ist.psu.edu/viewdoc/summary?

Sanchez-Guerrero, M. C., Lorenzo, P., Medrano, E., Castilla, N., Soriano, T., and Baille, A. (2005). Effect of variable $\mathrm{CO}_{2}$ enrichment on greenhouse production in mild winter climates. Agric. For. Meteorol. 132, 244-252. doi: 10.1016/j.agrformet.2005.07.014

Thongbai, P., Koai, T., and Ohyama, K. (2010). CO2 and air circulation effects on photosynthesis and transpiration of tomato seedlings. Sci. Hortic. 126, 338-344. doi: 10.1016/j.scienta.2010.07.018

Tingey, D. T., Waschmann, R. S., Phillips, D. L., and Olszyk, D. M. (2000). The carbon dioxide leakage from chambers measured using sulfur hexafluoride. Environ. Exp. Bot. 43, 101-110. doi: 10.1016/S0098-8472(99)00 051-9

Tong, Y., Kozai, T., and Ohyama, K. (2013). Performance of household heat pumps for nighttime cooling of a tomato greenhouse during the summer. Appl. Eng. Agric. 29, 415-422. doi: 10.13031/aea.29.9984

Tong, Y., Kozai, T., Ohyama, K., and Nishiyoga, M. (2010). Greenhouse heating using heat pumps with a high coefficient of performance (COP). Biosyst. Eng. 106, 405-411. doi: 10.1016/j.biosystemseng.2010.0 5.003 
Tong, Y., and Yang, Q. C. (2014). Analysis of electric-energy utilization efficiency in a plant factory with artificial light for lettuce production. Acta Hort. 1037, 277-284. doi: 10.17660/ActaHortic.2014.10 37.32

$\mathrm{Xu}$, H. L., Yamagishi, T., and Wada, Y. (1991). Interactive effect of soil water regime with above-ground conditions on photosynthesis in wheat plants. Crop Sci. Soc. Jpn. 60, 515-522. doi: 10.1626/jcs.6 0.515

Yang, Q. C., Wei, L. L., Liu, W. K., and Cheng, R. F. (2012). Plant Factories: Systems and Practice. Beijing: Chemical Industry Pub. Co.
Conflict of Interest Statement: The authors declare that the research was conducted in the absence of any commercial or financial relationships that could be construed as a potential conflict of interest.

Copyright (c) 2016 Wang, Tong, Yang and Xin. This is an open-access article distributed under the terms of the Creative Commons Attribution License (CC BY). The use, distribution or reproduction in other forums is permitted, provided the original author(s) or licensor are credited and that the original publication in this journal is cited, in accordance with accepted academic practice. No use, distribution or reproduction is permitted which does not comply with these terms. 